\title{
Brazilian Mothers' Description of their Children: Dimensions of Autonomy and Relatedness ${ }^{1}$
}

\author{
Maria Lucia Seidl-de-Moura ${ }^{2}$ \\ Deise Maria Leal Fernandes Mendes \\ Universidade do Estado do Rio de Janeiro \\ Mauro Luis Vieira \\ Universidade Federal de Santa Catarina \\ Ana Paula Korbarg \\ Faculdade Metropolitana de Blumenau \\ Luciana Fontes Pessôa \\ Pontifícia Universidade Católica do Rio de Janeiro \\ Tatiana Targino Alves Bandeira \\ Conselho Regional de Psicologia CRP/05
}

\begin{abstract}
Development of the self is oriented according to cultural models, such as: interdependent, independent, and autonomous-related. This study aimed to investigate how Brazilian mothers describe their children and the presence of autonomy and relatedness in their descriptions. Ninety-four mothers with children with ages ranging from 17 to 22 months were interviewed. The results indicate that mothers valued children being intelligent, active, loving and caring. Children were described with more positive than negative temperament characteristics. No significant difference was observed between the proportion of descriptors in the Independence and Relatedness category. This indicates a tendency towards an autonomous-related model, corroborating evidence of previous Brazilian studies. The present study brings evidence to socialization trajectories of Brazilian mothers and contributes to the literature on parental beliefs.
\end{abstract}

Key words: mothers' beliefs, autonomy, relatedness

\section{Descrição de seus Filhos por Mães Brasileiras: Dimensões de Autonomia e Relação}

\begin{abstract}
RESUMO - O desenvolvimento do selfé orientado por trajetórias de autonomia, interdependência e de autonomia relacionada. Este estudo visou investigar como mães brasileiras descrevem seus filhos e a presença de autonomia e relação em suas descrições. Mães ( $\mathrm{N}=94)$ com crianças de 17 a 22 meses de idade, foram entrevistadas. Os adjetivos mais usados foram inteligente e ativo, amoroso e carinhoso. As crianças foram descritas com mais características positivas de temperamento do que negativas. Não houve diferença significativa entre a proporção de descritores na categoria de independência e de interdependência, indicando a tendência para um modelo autônomo relacionado, corroborando resultados de estudos anteriores. O estudo traz evidências de trajetórias de socialização de mães brasileiras e contribui para a literatura sobre crenças parentais.
\end{abstract}

Palavras-chave: crenças maternas, autonomia, relação

Self development is oriented according to cultural models and in different trajectories. The task to conciliate personal goals, desires and motivations to the orientations of the cultural group to which one belongs is equated in different ways (Keller, 2012). This study aims to contribute to the literature on parenting and context, analyzing mothers' ideas about their children, assuming its importance because it has a direct relation to self development. Adopting a interactionist perspective (Keller, 2007), we are interested in aspects of the cultural environment that influence behavior and development, such as beliefs, concepts, rules, preferences and practices and their organization as communication codes, bodies of knowledge, competence, pleasure, and models of virtue (LeVine, 1989). It is the culture that constitutes the subjective frame of reference

1 Apoio: $\mathrm{CNPq}$

2 Endereço para correspondência: R. Fritz Feigl, 465, Rio de Janeiro, Brasil, CEP 22750-600.E-mail: mlseidl@gmail.com in which social and material conditions are experienced by children and the adults who take care of them. The environment is mediated by cultural categories.

Following this perspective, we use the concept of developmental niche, introduced by S. Harkness and C. Super (Harkness \& Super, 1994; Super \& Harkness, 1986, 1997) and its three subsystems: the social and physical environment (the child's daily life is structured in terms of place of residence and members of the family); shared care practices (including practices related to how the child should be cared for and that are shared by members of a culture); and the psychology of caretakers (beliefs and values about children's needs and about what is expected from them in the future). As the authors point out (Harkness \& Super, 2002), the three subsystems have the function of

being the mediators of development within the culture. They think that it is the regularities in the subsystems, as well as 
continuity along developmental stages that offer material for the child to infer the social, affective, and cognitive rules of the culture to which they belong (p. 272).

Keller (2007) and Kağitçibaşi (2007) complement Harkness and Super's model with the notion of general socialization or developmental trajectories, which can be considered adaptations to ecological and economic conditions. Depending on the context in which the family is inserted, different goals are established for children. In this way, cultural differences in parental care are widely documented (Keller, 2007). Contexts of care have been classified by Keller as dyadic or multiple in terms of social environment and as presenting co-active or exclusive structures of attention. According to these aspects, two main tendencies or trajectories can be observed: the one from traditional or rural societies has a multiple social environment and a co-active structure of attention. In this trajectory mothers perform their daily chores carrying their babies. On the other hand, in the urban educated way, socialization aims at an autonomous/independent self, social environment is dyadic, and the attention structure is exclusive. The baby is cared by one adult, usually the mother or a substitute, in an exclusive way. Generally, other activities are not performed while the adult is caring for the baby. According to Keller, these different trajectories orient the development of the self in diverse directions.

Kağitçibaşi (2005) adds to this contribution. To her, autonomy and relatedness are considered as basic human needs. Despite appearing conflicting, they are compatible (Kağitçibaşi, 2005). Furthermore, in an "integrative synthesis", Kağitçibaşi $(2007,2012)$ considers that autonomy and interdependency are not extreme points of a continuum. In this model, the basic dimensions are two: agency (from autonomy to heteronomy) and personal distance (from separation to connection). She proposes four types of development of the self resulting from the crossing of the two dimensions. The autonomous-related self is characterized by Kağitçibaşi (2007) as autonomous in terms of agency, but close in regard to the interpersonal distance. Thus, the relation with others, especially the family, is preserved. In the development of the autonomous/ independent self, relationship is distal, and face-to-face interactions and object stimulation are emphasized. According to both Keller (2007) and Kağitçibaşi (2007), this interactional pattern is typical of urban, western, educated middle-class families. In the developmental trajectory of interdependent selves, heteronomy and relationship to others are privileged, characterizing a proximal mode of relationship. Body contact and stimulation are predominant in this pattern, characteristic of rural families with low educational and socio-economic levels. The development of autonomous-related selves is typical of middle-class urban educated families from societies traditionally interdependent. Evidently, those are only general trajectories and a lot of differences in the balance between the value of autonomy and relatedness can be observed in different contexts.

Children develop relationships, construct knowledge and develop a self according to the extent in which autonomy and interdependency are differentially valued across all their lives and in the specific cultural contexts where they live. Cross-cultural studies have contributed to the understanding of different forms of parental beliefs and care (e.g. Citlak, Leyendecker, Schölmerich, Driessen, \& Harwood, 2008; Keller, Borke, \& Yovsi, 2005; Keller, et al., 2006), corroborating the hypotheses regarding these general trajectories and presenting data on differences between urban and non-urban, and traditional societies.

One important aspect of parental beliefs' system encompassed in these trajectories is the set of parental goals, or what they expect their children to become, oriented by what is generally valued in specific socio-cultural contexts. These goals are part of implicit ethnotheories, or systems of beliefs about children, ideal adults, and about what it is necessary for raising these ideal adults. Ethnotheories are negotiated and shared among members of communities and are translated into practices of care. Socialization goals are reflected in the socialization strategies adopted (Harwood, Schöelmerich, Ventura-Cook, Schulze, \& Wilson, 1996). Socialization goals can be of independence (success, self actualization, happiness) or interdependence (harmonious relationship with one's family, good behavior, respect to social norms etc), according to Harwood et al. (1996).

Studies have demonstrated the variety of ethnotheories or cultural models about children, family and care among different cultures (Harkness \& Super, 2002, 2005; Harkness, Super, Barry, Zeitlin, \& Long, 2009). These researchers investigate aspects of the developmental niche using several methodological approaches (observations, diaries, interviews etc.), and have studied families from Italy, Poland, Spain, Sweden, United States and Australia. In order to understand the implicit parental cultural models, Harkness and Super (2005) have asked mothers of the different countries to describe their children. They observed that "parents from different cultural communities talked about the personality and behavior of their children in different ways" (Harkness $\&$ Super, 2005, p. 65). The comparison among the descriptors used by parents of six of the seven cultures studied revealed different cultural models for children. American mothers emphasized cognitive and independence aspects; Italians highlighted pleasant temperament characteristics, Dutch mothers valued social and relational aspects, traits of persistence besides the capacity to "enjoy life"; and Swedish mothers frequently used the adjective "happy". In a previous study with Kipsigis' mothers from a rural community in western Kenya (Harkness \& Super, 2002; Harkness et al, 2009), they observed that mothers use terms that involved competence, a contextualized intelligence, in terms of effective functioning of the household, highlighting aspects of responsibility and helpfulness. The authors point out that the patterns observed in these descriptions indicate the social construction of qualities that are most important in each culture and diverse trajectories of development privileged.

Keller and Otto (2009) analyzed interview and observational data from two socio-cultural contexts, which respectively emphasize autonomy and relatedness: German middle-class and rural African Nso mothers who have children between 3 and 19 months old. Results showed differences in the cultural expectation regarding a "good child". For Nso mothers, a good child is calm, and does not express much his/her emotions, especially negative ones. These mothers overtly discourage the expression of this kind of emotions. 
On the other hand, German mothers value emotionally expressive children. They use a variety of strategies to facilitate children's compliance, including the negotiation with them as quasi-equal partners.

Brazilian studies have focused on socialization goals and beliefs about practices among groups in different cities of the country (Seidl-de-Moura et al., 2008; Seidl-de-Moura et al., 2009; Vieira, Seidl-de-Moura, Mafioletti et al., 2010; Vieira, Seidl-de-Moura, Lordelo et al., 2010) and between mothers who live in cities and rural contexts (Kobarg \& Vieira, 2008; Ruela, 2006). Seidl-de-Moura et al. (2009) studied the cultural models of a group of 200 mothers from Rio de Janeiro with children younger than 42 months of age. Participants answered the Socialization Goals Interview (SGI) (Harwood, 1992) and an Inventory about practices of care. The analyses of socialization goals indicated that these mothers share a model of autonomy, but also give importance to the relationship with others. The identified model also includes the concern about children's stimulation in several areas of their development, as well as their proper presentation in public. It is a model with specific characteristics and different from beliefs from mothers of different cultures, such as the German mothers in the study of Citlak et al. (2008). German mothers valued more self-control than self-maximization, differently from Brazilian mothers, who presented the opposite pattern. Brazilian mothers expect success for their children, especially professionally and economically, but keeping personal integrity and religious values, honesty and hard work. Mothers' educational level had differentiated their beliefs about autonomy. The ones with higher levels of education gave more importance to psychological well-being and the ones with lower levels of education valued more the development of children's personal and economic potential.

In a national study including seven different cities in Brazil, Seidl-de-Moura et al. (2009) identified a cultural model that includes values of autonomy and relatedness, suggesting a trajectory favoring the development of autonomous-related selves. The same model was observed by Bandeira, Seidl-de-Moura, and Vieira (2009) with fathers and mothers in Rio de Janeiro, Brazil. Fathers and mothers also shared goals of autonomy and of constructing good relationships to others. Vieira, Seidl-de-Moura, Mafioletti et al. (2010) studied a group of 606 women from 12 Brazilian cities (half of them from state capitals and the other half from small cities with less than 24,000 inhabitants). Comparing these groups, the authors noted differences in mothers' beliefs. Results indicate that although mothers from the two types of contexts gave importance to the development of their children's autonomy, mothers from small cities considered the relatedness dimension more important than the one of independence. Mothers living in state capitals valued equally the dimensions of autonomy and interdependency in their socialization goals and in their practices of care. Mothers from small cities presented a higher score of Family Allocentrism (Lay et al., 1998) than mothers from state capitals. In synthesis, this set of investigations supports a hypothesis that a balance of autonomy and relatedness is valued by Brazilian mothers from the contexts studied in their care of their children. Although recognizing that parents' educational level and experience of living in urban center may differentiate families somewhat, it seems that Brazilian may favor a trajectory leading toward the development of autonomous related selves. We believe that this trajectory and particular balance between autonomy and relatedness needs to be further explored with different instruments.

Thus, the present study aims to contribute to this line of investigation. Its objective is to analyze Brazilian mothers' beliefs about the importance of autonomy and relatedness present in their children's developmental niches. Previously studies have focused on socialization goals and beliefs about practices. This investigation considers mothers' ideas about their own children (17 to 22 months-old), as indicated in the descriptions provided when an open request is made. According to Harkness and Super (2005), this is a useful technique for researchers interested in parenting and culture and it is pleasant to the mothers. Harkness and Super (2006) also argue in favor of this strategy describing their cross-cultural study (ISPCS). We believe that data from Brazilian mothers who live in two urban contexts can contribute to the international literature on socialization trajectories and to the understanding of Brazilian development contexts.

\section{Method}

\section{Participants}

Mothers were recruited through daycare centers, nursery schools, hospitals and pediatricians. They were invited to participate in the study and, if they accepted, signed an Informed Consent Form. Data was collected trough individual interviews, generally at the participants' homes. Participants were 94 mothers. Forty-four lived in Rio de Janeiro, capital of the state with the same name, and 50 lived in Itajaí, Santa Catarina. Their ages ranged from 19 to 43 years old $(M=30.9$, $S D=5.8$ ), and they had children between 17 and 22 months old $(\mathrm{M}=18.99 \mathrm{mo}, S D=1.03 \mathrm{mo})$. Distribution of children according to sex was $56.4 \%$ of boys and $43.6 \%$ of girls. Participants' educational levels were: illiterate and incomplete elementary school (9.6\%), from complete elementary school to incomplete high school (12.8\%), from high school level to incomplete college education (37.2\%), and at least complete college $(40.4 \%)$. No significant differences were observed between educational levels of participants in the two cities and between the distributions of children by sex.

\section{Instrument and Procedures}

As part of a larger study, mothers were interviewed individually and were asked to talk about their target child, describing him/her. The instruction was: Tell me about your son/ daughter. How would you describe him/her? The interview was tape recorded and transcribed verbatim. Mothers could talk freely about their children and they were not limited in the number of descriptors they could use.

All the adjectives and expressions reported in the description were listed and constituted the corpus for analyses. For instance, one of the participants described her child with 
seven descriptors (smart, intelligent, active, affectionate, content, quiet, and shy), while other used just one descriptor: happy. The list of adjectives and expressions was used in two kinds of procedures for data reduction.

The first procedure was based on the studies that use the Socialization Goals Interview SGI (Seidl-de-Moura et al., 2009), although the categories were not previously defined, as in the SGI studies, but emerged from data. The steps in data reduction in this case were the following: first, through repeated readings of the children's descriptions, common patterns or categories were identified; descriptors were then classified based on these categories; the frequency of use of each category for each participant was computed; finally, a score for each category was obtained for all the participants, dividing the frequency of descriptors used in each category by all the descriptors. The second procedure was similar to the one used by Harkness and Super (2005). We analyzed the frequency of the adjectives and expressions present in the mothers' descriptions and the patterns that could be inferred from them.

Classification of the descriptors was done by two independent coders and there were no disagreements. In order to test the differences in mothers' scores in these categories, we performed $t$ tests for non independent samples, comparing pairs of mothers' scores in the different categories, such as Independence and Relatedness.

To examine the relationship between mothers' scores and some variables, such as mothers' and children's age, correlation analyses were run. Analyses were also done with the scores in Autonomy and Interdependence as dependent variables and educational levels as factors, using Full Factorial Multivariate GLM, with $p<.05$ and Power $>.70$. Post hoc test were performed comparing different educational levels. The study followed Brazilian regulations for research with Human Subjects and it was approved by ethical committees in the two universities involved.

\section{Results}

Mothers had no difficulties in answering the solicitation presented and engaged in free descriptions of their children. The adjectives used in their answers were identified. The mean number of descriptors used was 4.97 by mothers of Rio de Janeiro, and 4.38 from Itajaí. A total of 437 descriptors were employed, being 115 different adjectives. There was substantial variation across mothers in the number and content of utterances. Despite this great variety, some general tendencies could be observed. The first one was that, in general, this group of mothers listed positive characteristics of their children (with 75 different adjectives), although 35 negative characteristics were evoked, related to both children's temperament and externalization behaviors.

The five adjectives most frequently used were loving/caring (carinhoso) $(\mathrm{n}=49)$; smart (esperto) $(\mathrm{n}=26)$; intelligent (inteligente) $(\mathrm{n}=21)$; energetic/reckless (agitado) $(\mathrm{n}=22)$ and active (ativo) $(\mathrm{n}=18)$. When we combine them we reach a profile of two main characteristics and a third secondary one: warm $(n=49)$; intelligent / smart / active $(n=65)$ and energetic (reckless) $(n=22)$. Examining the adjectives most
Table 1. Number of descriptors used in each category and \% of the total

\begin{tabular}{lcc}
\hline Category & $\begin{array}{c}\text { Number of different } \\
\text { descriptors }\end{array}$ & \% of total \\
\hline Independence & 21 & 18.42 \\
Relatedness & 18 & 15.78 \\
Positive temperament & 18 & 15.78 \\
Negative temperament & 11 & 7.00 \\
Introversion & 5 & 4.38 \\
Externalization & 22 & 19.30 \\
Others & 19 & 16.67 \\
\hline
\end{tabular}

frequently adopted, we can observe that mothers value their children being intelligent and active, as well as the fact that they are loving or caring.

In order to further analyze mothers' conceptions of their children and the cultural models implicit in them, the corpus was coded in seven categories: Independence/ autonomy (e.g. active; smart; intelligent; independent; strong; determined); Relatedness (e.g. collaborative, kind, nice); Positive temperament (e.g. happy; sweet, easy going; calm); Negative temperament (e.g. bad-tempered; annoying; stressed); Introversion (e.g. shy; inhibited), Externalization (e.g. aggressive; disobedient; destructive); and others (e.g. healthy; loved; blessed). The number of different adjectives used in each category and the percentage of occurrence are presented in Table 1.

This categorization supports the inference of a model of related autonomy. The proportion of descriptors in the category Independence is 18.42 , while the one in the category Relatedness / Interdependence is 15.78. Besides this tendency, it seems to be present a difficulty of mothers to promote their children's self-regulation, as indicated by the percentage of descriptors in the Externalization category.

Correlations between the scores in each category yielded significant results $(p<.05)$. For example, there is a negative correlation between Independence and Relatedness $(r=-.41)$. The more the mother describes her child with independence characteristics, the less she describes him/her as interdependent. Another relation observed was between Independence and Externalization scores $(r=-.25)$. The more mothers see their children as independent, the less they use Externalization or Positive temperament descriptors $(r=-.24)$. They seem to be focused on autonomy when perceiving their children. The same happens with Relatedness (or interdependence scores). The more the mother uses relatedness adjectives to talk about her child, the less she uses positive $(r=-.23)$, or negative $(r=-.20)$, characteristic descriptors. Externalization is also negatively related to positive temperament characteristics $(r=-.31)$. There were no significant correlations between scores in the categories and mothers' or children's age.

To test differences in mothers' scores, we performed paired samples (non independent) $t$ tests, comparing pairs of scores in the different categories. Results are presented in Table 2. The first result, confirming previous ones, is the absence of differences between scores in Independence and Relatedness, thus indicating a tendency of these mothers to 
Table 2. Paired Sample $t$ tests between the Scores on the Different Categories.

\begin{tabular}{llcccccc}
\hline Pairs & & Mean & $s d$ & Std. Error Mean & $t$ & df & Sig. \\
\hline 1 & Independence/Relatedness & .04 & .42 & .04 & .86 & 93 & $\mathrm{~ns}$ \\
\hline 2 & Independence/Externalization & .12 & .38 & .04 & 2.80 & 93 & $p=.006$ \\
\hline 3 & Independence - Introversion & .26 & .26 & .03 & 9.59 & 92 & $p=.000$ \\
\hline 4 & Independence - Positive temp. & .07 & .40 & .04 & 1.71 & 93 & $\mathrm{~ns}$ \\
\hline 5 & Independence - Negative temp. & .22 & .31 & .03 & 6.84 & 93 & $p=.000$ \\
\hline 6 & Relatedness - Externalization. & .07 & .35 & .04 & 1.98 & 93 & $\mathrm{~ns}$ \\
\hline 7 & Relatedness - Introversion & .23 & .24 & .03 & 8.94 & 92 & $p=.000$ \\
\hline 8 & Relatedness - Positive temp. & .03 & .38 & .04 & .834 & 93 & $\mathrm{~ns}$ \\
\hline 9 & Relatedness - Negative temp. & .18 & .30 & .03 & 5.69 & 93 & $p=.000$ \\
\hline 10 & Externalization - Introversion & .16 & .21 & .02 & 7.04 & 92 & $p=.000$ \\
\hline 11 & Externalization - Positive temp. & -.04 & .37 & .04 & -1.03 & 93 & $\mathrm{~ns}$ \\
\hline 12 & Externalization - Negative temp. & .11 & .26 & .03 & 3.94 & 93 & $p=.000$ \\
\hline 13 & Introversion - Positive temp. & -.19 & .24 & .03 & -7.63 & 92 & $p=.000$ \\
\hline 14 & Introversion - Negative temp. & -.05 & .14 & .01 & -3.26 & 92 & $p=.002$ \\
\hline 15 & Positive temp. - Negative temp & .15 & .30 & .03 & 4.70 & 93 & $p=.000$ \\
\hline & & & & & & 93 \\
\hline
\end{tabular}

see their children with characteristics of an autonomous-related self. There are no differences also between the scores in Independence and Positive temperament; Relatedness and Externalization; Externalization and Positive temperament. Children are described with more positive than negative characteristics of temperament, and with more Externalization than Introversion characteristics. There was also a significant difference between means on Introversion and Negative temperament scores.

The effect of educational level (codified in four levels) in mothers' scores on Independence and Relatedness was tested using a Multivariate (Full factorial GLM analyses). There was no significant effect of educational level in both dependent variables. Since the effect of educational level was not significant, there was no sense in performing post hoc tests, but we compared the means in the two scores from mothers of the two most extreme educational levels and there were no significant results. Thus, in this group, mothers' descriptions of their children as more autonomous or more interdependent do not seem to be affected by their educational level. However, we have to look to this result with caution, since it may be the consequence of lack of power to test the hypothesis, due to insufficient sample size.

\section{Discussion}

This study can be considered a small contribution that complements a series of investigations about Brazilian parenting models. It used a simple technique that has advantages and limitations and that has been successfully used in the literature. Asking mothers to describe their children we hoped to be able to infer the qualities that were most salient and that they value most in them. This would enable us to infer some of their beliefs. The corpus of answers was content-analyzed and we were able to observe the attributes most cited and group them in categories.
From the three groups of adjectives most frequently used by mothers - warm, intelligent/smart, and agitated energetic/ active -, we can infer a pattern that includes similar characteristics to the ones observed in other contexts. Harkness and Super (2005) found similar results in mothers from Australia, Italy, Holland, Spain, Sweden, and United States. In these countries, the qualities of being active and loving were constant and therefore included by the authors in the group of common descriptors. The characteristic intelligent, however, was frequently mentioned only by Australian, Spanish and North American mothers. Those were urban groups of mothers, such as the ones in our study. Maybe those are characteristics that mother tend to cite when asked to talk about their children. However, although common, the proportion in which they were cited in each country was different in Harkness and Super (2005). It was also different from the ones mentioned by African Kipsigis mothers (Harkness et al, 2009).

We believe that when we consider the results of the analyses that compared the categories of interdependency and autonomy, we can infer a profile that emphasizes both dimensions, thus indicating the possible promotion of the development of related autonomy, as proposed by Kağitçibaşi (2007). This finding corroborates previous studies with Brazilian mothers (Bandeira et al., 2009; Seidl-de-Moura et al., 2008, 2009; Vieira, Seidl-de-Moura, Mafioletti et al., 2010; Vieira, Seidl-de-Moura, Lordelo et al., 2010). Valuing both autonomy and relatedness seems to be a characteristic of mothers from different contexts in Brazil (Seidl-de-Moura et al., 2008) have found that Brazilian mothers expect their children to be happy, healthy, confident, and assertive, to make good decisions, and to have a good education. Differences can be observed from the results obtained by Keller and Otto (2009) with middle-class mothers in Germany, who had high scores for socialization goals related to their children's autonomy.

Although presenting some relevant evidence about the pattern of beliefs of two groups of Brazilian mothers, this stu- 
dy has limitations. Obviously, the sample is not representative of Brazilian mothers with babies 17 to 22 months old. Only a group of mothers from urban contexts (two cities) was interviewed. In addition, the group of participants was relatively homogeneous in relation to the socio-demographic variables considered. The technique used was only an open question and mothers' beliefs could have been further explored, asking them to rank them in terms of importance or to describe an ideal child. Certainly, more studies are necessary, including mothers from other cities with different urbanization levels from diverse Brazilian regions and also fathers who have not been studied much. Further studies can broaden this focus, bringing more data about Brazilian mothers' and fathers belief systems aiming to understand their parenting cultural models. They could be complemented by investigations that attempt to correlate these models with practices of care and the quality of mother-child interactions.

\section{References}

Bandeira, T. T., Seidl-de-Moura, M. L., \& Vieira, M. L. (2009). Metas de socialização de pais e mães para seus filhos. [Mothers' and father's socialization goals for theirs children]. Revista Brasileira de Crescimento e Desenvolvimento Humano, 19(3), 445-456.

Citlak, R., Leyendecker, B., Schölmerich, A., Driessen, R., \& Harwood, R. L. (2008). Socialization goals among first - and second-generation migrant Turkish and German mothers. International Journal of Behavioral Development, 32(1), 57-66.

Harkness, S., \& Super, C. M. (1994). The developmental niche: A theoretical framework for analyzing the household production of health. Social Science \& Medicine, 38(2), 217-226.

Harkness, S., \& Super, C. M. (2002). Culture and parenting. In M. H. Bornstein (Ed.), Handbook of parenting, Vol. 2: Biology and ecology of parenting (2nd ed., pp. 253-280). Mahwah, NJ: Lawrence Erlbaum.

Harkness, S., \& Super, C. M. (2005). Themes and variations: Parental ethnotheories in Western cultures. In K. Rubin, \& O. B. Chung (Eds.), Parental beliefs, parenting, and child development in cross-cultural perspective (pp. 61-79). New York: Psychology Press.

Harkness, S., Super, C. M., Barry, O., Zeitlin, M., \& Long, J. (2009). Assessing the environment of children's learning: The development niche in Africa. In E. L. Gicorenko (Ed.), Multicultural psychoeducational assessment (pp. 133-156). New York: Springer Publishing Company.

Harwood, R. L. (1992). The influence of culturally derived values on Anglo and Puerto Rican mothers' perception of attachment behavior. Child Development, 63, 822-839.

Harwood, R. L., Schöelmerich, A., Ventura-Cook, E., Schulze, P. A., \& Wilson, S. P. (1996). Culture and class influences on Anglo and Puerto Rican mothers' beliefs regarding long-term socialization goals and child behavior. Child Development, $67,2446-2461$.
Kağitçibaşi, C. (2005). Autonomy and relatedness in cultural context: Implications for self and family. Journal of CrossCultural Psychology, 36, 403-422.

Kağitçibaşi, C. (2007). Family, self and human development across cultures: Theory and applications. Mahwah, NJ: Erlbaum.

Kağitçibaşi, C. (2012). Socio-cultural change and integrative syntheses in human development: Autonomous-related self and social-cognitive competence. Child Development Perspectives, 6, 5-11. doi: 10.1111/j.1750-8606.2011.00173.x

Keller, H. (2007). Cultures of infancy. Mahwah, NJ: Lawrence Erlbaum Associates.

Keller, H. (2012). Autonomy and relatedness revisited: cultural manifestations of universal human needs. Child Development Perspectives, 6(1), 12-18. doi: 10.1111/j.17508606.2011.00208.x

Keller H, Borke J, Yovsi R. (2005). Cultural orientations and historical changes as predictors of parenting behaviour, International Journal of Behavior Development, 29(3), 229-237.

Keller, H., Lamm, B., Abels, M.,Yovsi, R. D., Borke, J., Jensen, H.,... \& Chaudry, N. (2006). Cultural models, socialization goals, and parenting ethnotheories: A multi-cultural analysis. Journal of Cross-Cultural Psychology, 37(2), 155-172

Keller, H., \& Otto, H. (2009). The cultural socialization of emotion regulation during infancy. Journal of Cross-Cultural Psychology, 40(6), 996-1011.

Kobarg, A., \& Vieira, M. L. (2008). Crenças e práticas de mães sobre o desenvolvimento infantil nos contextos rural e urbano [Mothers' beliefs and practices about child development in rural and urban contexts] Psicologia: Reflexão e Crítica, 2(3), 401-408.

LeVine, R. A. (1989). Cultural environments in child development. In W. Damon (Ed.), Child development today and tomorrow (pp. 52-68). San Francisco: Jossey-Bass.

Ruela, S. F. (2006). Um estudo intergeracional de crenças valorizadas por mães em uma comunidade rural do estado do Rio de Janeiro. [A intergerational study on values beliefs by mothers in a rural community in Rio de Janeiro State, Brazil]. (Unpublished master's thesis), Universidade do Estado do Rio de Janeiro, Rio de Janeiro, Rio de Janeiro, Brazil.

Seidl-de-Moura, M. L., Targino, T., Nahum, K., Cruz, E. M., Amaral, G., \& De Marca, R. (2009). Parenting cultural models of a group of mothers from Rio de Janeiro, Brazil. The Spanish Journal of Psychology, 12(2), 506-517.

Seidl-de-Moura, M. L., Lordelo, E., Vieira, M. L., Piccinnini, C. A., Siqueira, J. E O., Magalhães, C. M. C. \& Rimoli, A. (2008). Brazilian mothers' socialization goals: Intracultural differences in seven cities. International Journal of Behavioral Development, 32(6), 465-472.

Super, C., \& Harkness, S. (1986). The developmental niche: A conceptualization at the interface of child and culture. International Journal of Behavioral Development, 9, 545-569.

Super, C. M. \& Harkness, S. (1997). The cultural structuring of child development. In J. W. Berry, P. R. Dasen \& T. S. Saraswathi (Eds), Handbook of cross-cultural psychology, second edition. Vol. 2 : Basic processes and human development (pp. 1-39). Boston : Allyn \& Bacon. 
Vieira, M. L., Seidl-de-Moura, M. L., Lordelo, E., Piccinnini, C. A., Martins, G. D., Macarini, S. M. ... Rímoli, A.O. (2010). Brazilian mother's beliefs about childrearing practices. Journal of Cross-Cultural Psychology, 41(2), 195-211.

Vieira, M. L., Seidl-de-Moura, M. L., Lordelo, E., Piccinnini, C. A., Martins, G. D., Macarini, S. M., et. al. (2010). Brazilian mother's beliefs about childrearing practices. Journal of CrossCultural Psychology, 41(2), 195-211.

Recebido em 03.10.2011

Primeira decisão editorial em 21.06.2012

Versão final em 06.07.2012

Aceito em 25.07.2012 